\section{(6) OPEN ACCESS}

\title{
Novel aspiration catheter design for acute stroke thrombectomy
}

\author{
Troy D Long, ${ }^{1}$ David F Kallmes, ${ }^{2}$ Ricardo Hanel, ${ }^{3}$ Tomoyoshi Shigematsu, ${ }^{4}$ \\ Alexander Michael Halaszyn, ${ }^{5}$ Julia Wolter, ${ }^{5}$ Alejandro Berenstein ${ }^{4}$
}

${ }^{1}$ North Memorial Medical

Center, Robbinsdale, Minnesota, USA

${ }^{2}$ Mayo Clinic, Rochester,

Minnesota, USA

${ }^{3}$ Baptist Health, Jacksonville,

Florida, USA

${ }^{4}$ Mount Sinai Health System, New York City, New York, USA

${ }^{5}$ University of Minnesota,

Minneapolis, Minnesota, USA

\section{Correspondence to}

Dr Troy D Long, North Memorial

Medical Center, Robbinsdale,

MN 55422, USA; tlong@

mplsrad.com

Received 16 January 2018

Revised 29 May 2018

Accepted 4 June 2018

Published Online First

30 July 2018

\section{ABSTRACT}

Background Navigable, large diameter aspiration catheters demonstrate markedly improved recanalization rates over smaller lumen devices in suction embolectomy. We evaluated the performance of a novel aspiration catheter system designed to maximize lumen size, and compare it to other commercially available aspiration catheters.

Methods The $6 \mathrm{~F} \mathrm{R}{ }^{4} \mathrm{Q}$ aspiration catheter system comprises a proximal pusher wire of $117 \mathrm{~cm}$ length connected to a distal catheter of $25 \mathrm{~cm}$ length. When placed through standard guide catheters and into the cerebral circulation, the proximal catheter makes a tight seal between its outer surface and the guide catheter's inner surface. During aspiration, in vitro flow rates and tip suction force under gentle retraction were compared among 10 commercially available aspiration catheters and the $R^{4} Q$ system.

Results The $R^{4} \mathrm{Q} 6 \mathrm{~F}, 5 \mathrm{~F}, 4 \mathrm{~F}$, and $3 \mathrm{~F}$ catheters achieved flow rates at least $21.9 \%, 24.7 \%, 61.9 \%$, and $244.7 \%$ greater than the other catheters tested respectively and the $R^{4} Q 6 F$ produced a $140.2 \%$ higher tip force than a catheter of similar size. Fluid flow rate in the $R^{4} Q 6 F$ increased on retraction into the guide catheter, delivering a $58.2 \%$ increase from fully extended to fully retracted. Conclusion The $R^{4} Q$ design demonstrates a substantial increase in aspirated flow rate and suction force due to an increased effective diameter than standard tubular catheter designs tested. The prominent increase in the aspiration parameters measured in vitro supports the potential for improved clinical results during stroke thrombectomy procedures.

\section{INTRODUCTION}

In 2015, five prospective, randomized trials confirmed the superiority of endovascular thrombectomy over medical management for the treatment of acute ischemic stroke. ${ }^{1-5}$ Recently, a survey of neurointerventionalists reported the most common first-line mechanical thrombectomy approach to be the direct aspiration first-pass (ADAPT) technique. ${ }^{6}$ This approach involves the removal of clot via an aspiration catheter connected to an external suction source. The availability of effective suction to the middle cerebral arteries (MCA) and beyond during ADAPT is challenging to ensure, and essential to, the successful removal of thrombus. While advances in aspiration catheter performance have been associated with faster procedure times, higher recannulation rates and better outcomes, ${ }^{7-14}$ failure to recanalize with currently available aspiration catheters occurs in approximately one-third of patients. ${ }^{15} 16$

Based on current data, it is possible that larger suction aspiration catheters are correlated with improved recanalization. ${ }^{11} 14 \quad 17$ Catheters with tapered, large bore designs have been introduced to harness the benefits of an increased tip surface area. Alternatively, a new catheter design effectively increases inner diameter for the entire system. We sought to evaluate these new suction catheters, all compatible with standard guiding catheters, that would retain, or even improve on, the navigability of current suction catheters yet profoundly increase the suction efficiency based on larger inner diameters.

\section{METHODS}

\section{Catheter design}

Due to neurovascular vessel size constraints, the design of an effective aspiration catheter often involves a tradeoff between suction strength and ability to access the distal neurovasculature. While improved suction power has been associated with larger diameter catheters, ${ }^{18-22}$ thrombi are often located in highly tortuous, small diameter vessels. As a compromise, the implementation of a tapered design is common. The distal tip of the aspiration catheter is smaller than the proximal shaft, maximizing both suction capability and distal access. This design approach is ultimately limited by the inner diameter (ID) of the required guide catheter and the minimum wall thickness of the aspiration catheter. The $\mathrm{R}^{4} \mathrm{Q}$ aspiration catheter (MIVI Neuroscience, Inc., Eden Prairie, MN) design overcomes these limitations by eliminating the proximal three-quarters of the catheter shaft and replacing it with a $117 \mathrm{~cm}, 0.018$ inch stainless steel control wire. This enables the utilization of the full internal area of the guide catheter for the delivery of suction power (figure 1 ). A $\mathrm{R}^{4} \mathrm{Q}$ family has an outer diameter (OD) along the proximal catheter segments of 0.088 inch, with distal ODs of 0.082 inch, 0.072 inch, 0.055 inch, and 0.048 inch and named as $R^{4} Q$ $6 \mathrm{~F}, 5 \mathrm{~F}, 4 \mathrm{~F}$, and 3F, respectively. Similar to standard aspiration catheter designs, the $\mathrm{R}^{4} \mathrm{Q}$ is delivered to the clot site via a micro-wire and micro-catheter within an $8 \mathrm{~F}$ guide catheter $/ 6 \mathrm{~F}$ sheath. Unlike standard designs, suction is applied directly to the guide catheter and the total system length is variable as the $R^{4} \mathrm{Q}$ is extended outward and retracted into the guide catheter. 


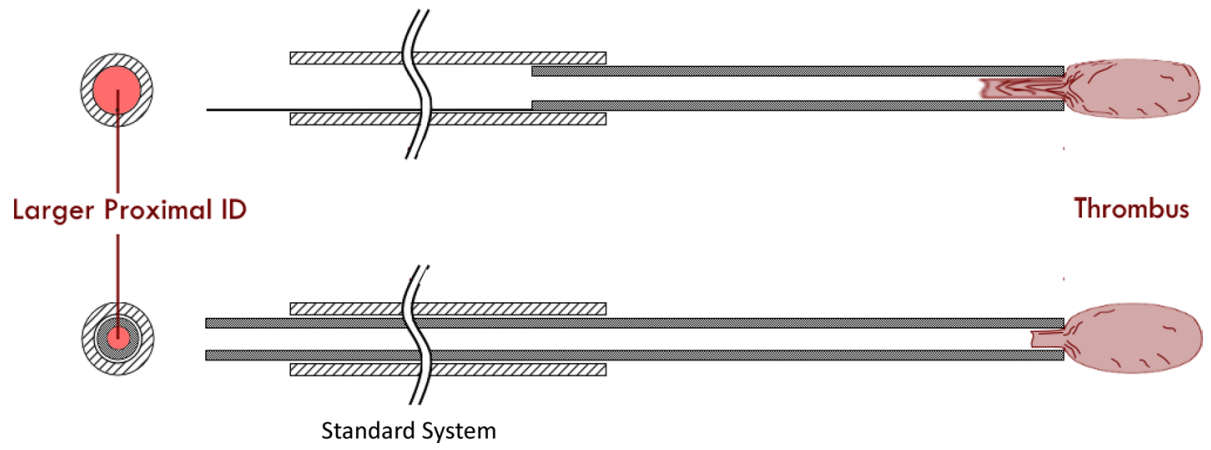

Figure 1 Conceptual schematic of the $\mathrm{R}^{4} \mathrm{Q}$ friction fit into distal end of the guide catheter compared with the standard aspiration catheter system. The control wire (solid black) occupies less volume than the standard catheter within the guide catheter. Note: dimensions are not to scale.

The $\mathrm{R}^{4} \mathrm{Q}$ was designed to maximize flow and minimize pressure loss. In fluid dynamics, all primary relationships are defined by a set of fundamental equations called the NavierStokes Equations. These equations further simplify to relate fluid properties (viscosity), channel geometry (length and ID), and hydraulic characteristics (flow rate and pressure loss) in an equation known as the Hagen-Poiseuille Law (HPL). This relationship applies to nonaccelerating fluid in a tube of consistent diameter. $^{23}$

Hagen-Poiseuille Law

$$
\mathrm{Q}=\frac{\pi r^{4} \Delta P}{8 \eta L}
$$

where $\mathrm{Q}=$ volumetric flow rate, $\pi=$ constant $\mathrm{pi}, \mathrm{r}=$ inner radius, $\Delta P=$ pressure drop, $\eta=$ liquid viscosity, and $\mathrm{L}=$ length of tube.

Improvement of thrombus aspiration requires increased flow-derived vacuum to achieve greater suction transmission through the catheter. According to the HPL, the variable leveraging the greatest effect on flow-derived vacuum is the mean ID of the device. Since even a small increase in ID results in significant increases in flow rate, the $R^{4} Q$ was designed to achieve aspiration rates and forces greater than standard catheter designs. Prior scientific examination has similarly established the powerful relationship of ID to pressure loss and flow rate in small vessels. ${ }^{18} 2425$ We sought to compare these factors in the $\mathrm{R}^{4} \mathrm{Q}$ and other catheters in vitro.

\section{Vacuum flow rate}

To empirically examine the performance of this novel design, we tested all sizes of the $R^{4} Q$ against 10 commercially available catheters (table 1). A representative effective ID was calculated for each catheter using the corresponding proportion of the distal and proximal IDs to account for the non-uniform IDs. The $\mathrm{R}^{4} \mathrm{Qs}$ ' distal IDs refer to the distal portion of the system, while the proximal IDs correspond to the guiding catheter used in the system. Other tapered catheters' effective IDs were approximated with a $10 \%$ distal ID, $90 \%$ proximal ID proportion of the working length. The effective IDs are listed in table 1 for reference. Following a method previously described by $\mathrm{Hu}$ and Stiefel (figure 2A), ${ }^{26}$ a Gomco aspiration pump Model $4005 \mathrm{P}$ (Allied Healthcare Products, St. Louis, MO) was set to deliver $600 \mathrm{mmHg}$ of vacuum through $2.794 \mathrm{~mm}$ (0.110 inch) ID aspiration tubing (MIVI Neuroscience, Inc.) with a standard in-line valve and lure fittings. The $R^{4} Q$ was used in combination with a Super 90 guide catheter 8F (MIVI Neuroscience, Inc.), which has an ID of 0.090 inch, OD of 0.114 inch, and length of $90 \mathrm{~cm}$. When the vacuum pressure attained a steady state, the valve was released allowing room-temperature water to be aspirated by the catheter into the pump collection canister. An electronic switch shut off the pump after $110 \mathrm{~s}$, and the aspirated fluid was weighed. Standard values for water density were used to calculate the mean volumetric flow rate through the catheter by dividing aspirated fluid weight by time. This process was repeated three times and averaged for each catheter tested. The SD for each sample population never exceeded $1 \%$ of the measured average.

Since the $R^{4} Q$ catheter is not one continuous tube throughout its length, this introduces the possibility of liquid entering the system at the junction between the $\mathrm{R}^{4} \mathrm{Q}$ shaft and the guide catheter. To observe this phenomenon, the catheter tip was obstructed with a ga pin and the flow rate was measured with the $R^{4} Q$ and guide catheter junction submerged in open water. This flow rate, $4.9 \mathrm{~mL} / \mathrm{min}$, calculates to $1.52 \%$ of the aspirated volume when the catheter tip is fully patent. Therefore, to account for a worstcase scenario in which all vacuum pressure is focused on the junction, we decreased the $\mathrm{R}^{4} \mathrm{Q}$ flow rates by $1.52 \%$.

\section{Tip force}

In addition to dynamic flow rate, the force at the catheter tip was measured by simulating a corked tip condition. The setup is depicted in figure 2B. A 0.068 inch pin ga was inserted in the distal tip to create a nearly obstructed flow path after the system was flooded with room temperature tap water. The pin gauge was attached via a hemostasis valve to a digital force gauge (Ametek Chatillon, Berwyn, PA, USA) and aligned with the aspiration catheter tip. The junction between the $R^{4} Q$ and guide catheter was submerged in a fluid-filled closed tube to control the pressure and isolate the force measurement at the tip. Aspiration was applied to the guide catheter using the setup previously described and adjusted to $600 \mathrm{mmHg}$ of vacuum. The force gauge and pin gage were pulled from the tip and the maximum gram force was recorded. The $R^{4} Q$ was used with a Super 90 guide catheter $8 \mathrm{~F}$ and compared headto-head with a Penumbra ACE 68 in the identical setup with aspiration directly connected to the ACE 68. For both catheters, the forces were also measured in the same configuration without aspiration to determine the force due to friction between the pin gage and the catheter tip. These forces were averaged and subtracted from measurements with aspiration to find the force attributed to aspiration in the catheter.

\section{Impact of retraction on flow rate}

As the nozzle tip of the $\mathrm{R}^{4} \mathrm{Q}$ system is withdrawn into the guide catheter, the overall length of the fluid path decreases. The 


\begin{tabular}{|c|c|c|c|c|c|c|c|}
\hline Outer diameter & Catheter & Company & Distal ID (in) & Proximal ID (in) & Distal area $\left(\mathrm{in}^{2}\right)$ & Length of tube $(\mathrm{cm})$ & Effective ID (in) \\
\hline \multirow[t]{8}{*}{$6 F$} & $R^{4} Q 6 F$ & MIVI Neuroscience, Inc. & 0.069 & $0.090^{*}$ & 0.0037 & 115 & 0.0854 \\
\hline & & Eden Prairie, MN & & & & & \\
\hline & Sophia Plus & MicroVention Terumo & 0.07 & 0.07 & 0.0038 & 131 & 0.0700 \\
\hline & & Tustin, CA & & & & & \\
\hline & ACE 68 & Penumbra & 0.068 & 0.068 & 0.0036 & 132 & 0.0680 \\
\hline & & Alameda, $C A$ & & & & & \\
\hline & ACE 064 & Penumbra & 0.064 & 0.068 & 0.0032 & 132 & 0.0672 \\
\hline & & Alameda, $C A$ & & & & & \\
\hline \multirow[t]{12}{*}{$5 F$} & $R^{4} Q 5 F$ & MIVI Neuroscience, Inc. & 0.057 & $0.090^{*}$ & 0.0026 & 115 & 0.0828 \\
\hline & & Eden Prairie, MN & & & & & \\
\hline & ARC & Medtronic & 0.061 & 0.069 & 0.0029 & 132 & 0.0682 \\
\hline & & Minneapolis, MN & & & & & \\
\hline & Mi-Axus 6 & MIVI Neuroscience, Inc. & 0.057 & 0.064 & 0.0026 & 128 & 0.0633 \\
\hline & & Eden Prairie, MN & & & & & \\
\hline & InNeuroCo & Codman Neuro & 0.06 & 0.064 & 0.0028 & 125 & 0.0636 \\
\hline & & Raynham, MA & & & & & \\
\hline & 5MAX ACE & Penumbra & 0.056 & 0.064 & 0.0028 & 132 & 0.0636 \\
\hline & & Alameda, $C A$ & & & & & \\
\hline & $5 \mathrm{MAX}$ & Penumbra & 0.054 & 0.064 & 0.0023 & 128 & 0.0630 \\
\hline & & Alameda, $C A$ & & & & & \\
\hline \multirow[t]{4}{*}{$4 \mathrm{~F}$} & $R^{4} Q 4 F$ & MIVI Neuroscience, Inc. & 0.043 & $0.090^{*}$ & 0.0015 & 120 & 0.0778 \\
\hline & & Eden Prairie, MN & & & & & \\
\hline & 4MAX & Penumbra & 0.041 & 0.064 & 0.0013 & 139 & 0.0617 \\
\hline & & Alameda, CA & & & & & \\
\hline \multirow[t]{4}{*}{$3 F$} & $R^{4} Q 3 F$ & MIVI Neuroscience, Inc. & 0.036 & $0.090^{*}$ & 0.00102 & 125 & 0.0768 \\
\hline & & Eden Prairie, MN & & & & & \\
\hline & 3 MAX & Penumbra & 0.035 & 0.043 & 0.00096 & 153 & 0.0422 \\
\hline & & Alameda, CA & & & & & \\
\hline
\end{tabular}

*Guide catheter ID is used as the proximal ID dimension of the $\mathrm{R}^{4} \mathrm{Q}$ system.

effects of these factors positively contribute to flow rate (Q) in the HPL. In order to quantify this phenomenon, flow rate was measured as the $\mathrm{R}^{4} \mathrm{Q}$ was retracted within an $8 \mathrm{~F}$ guide catheter. The flow rate was measured at full extension from the guide catheter. The $\mathrm{R}^{4} \mathrm{Q}$ was then retracted in $5 \mathrm{~cm}$ increments until it was fully inside the guide catheter. Flow rates were measured in five repetitions at each retraction point. The same procedure was performed with a similarly sized standard catheter.
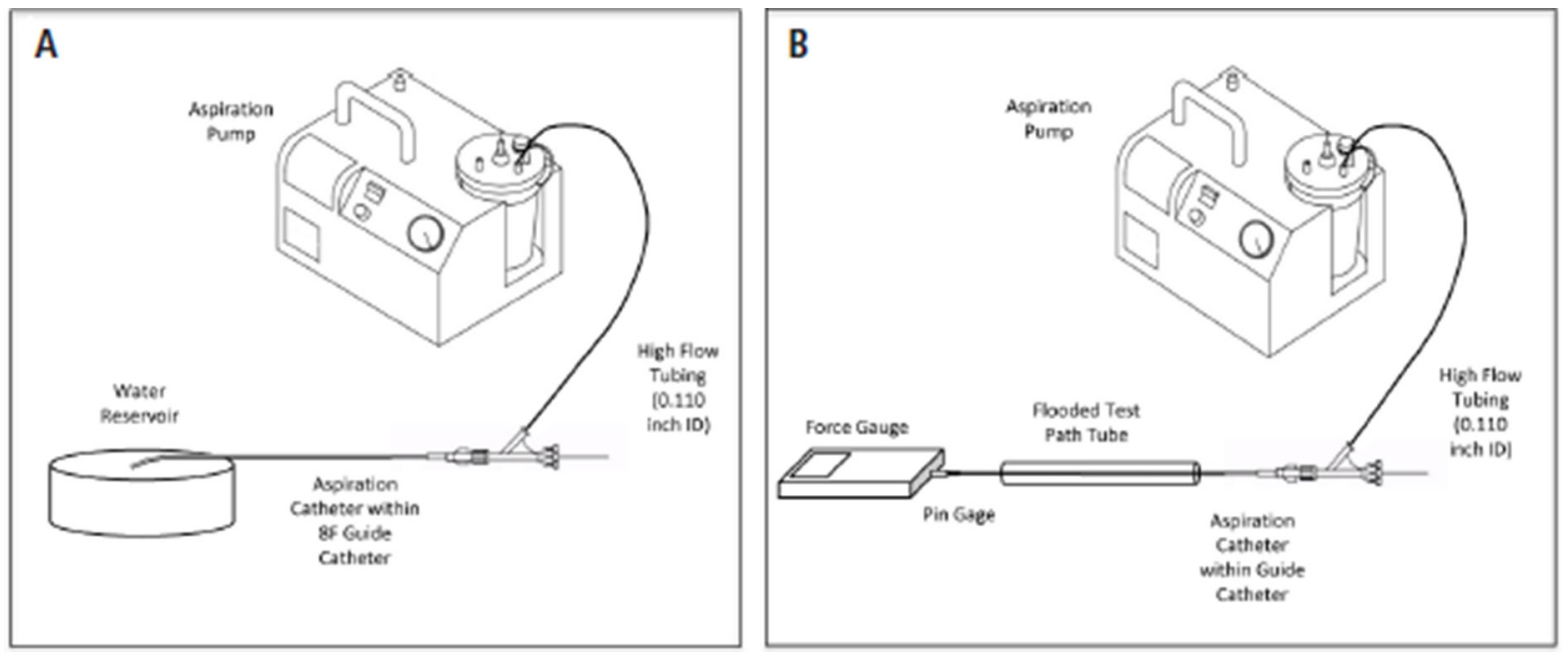

Figure 2 Schematic of experimental setup for vacuum flow rate (A) and tip force measurements (B). 


\begin{tabular}{|c|c|}
\hline Catheter & Flow rate $(\mathrm{mL} / \mathrm{s})$ \\
\hline$R^{4} Q 6 F$ & 5.31 \\
\hline Sophia plus & 4.42 \\
\hline ACE 068 & 4.27 \\
\hline ACE 064 & 4.36 \\
\hline$R^{4} Q 5 F$ & 4.93 \\
\hline ARC & 4.01 \\
\hline Mi-Axus 6 & 3.82 \\
\hline InNeuroCo 6F & 3.48 \\
\hline 5MAX ACE & 3.60 \\
\hline $5 \mathrm{MAX}$ & 3.00 \\
\hline$R^{4} Q 4 F$ & 3.89 \\
\hline 4MAX & 2.44 \\
\hline R4Q 3F & 3.50 \\
\hline 3 MAX & 1.03 \\
\hline
\end{tabular}

\section{Statistics}

In the flow rate experimental setup, only three repetitions were necessary for each catheter tested due to low variability. All tests were performed with consistent experimental conditions in an attempt to limit confounding variables. An additional sequence of 10 flow tests was completed on the $\mathrm{R}^{4} \mathrm{Q} 6 \mathrm{~F}$ and $\mathrm{ACE} 68$ to confirm the validity of the results.

\section{RESULTS}

\section{Vacuum flow rate}

Table 2 and figure $3 \mathrm{~A}$ summarize the flow rate collected by this method. The $\mathrm{R}^{4} \mathrm{Q}$ exhibited higher flow rates than other commercially available catheters tested.

\section{Tip force}

Figure $3 \mathrm{~B}$ portrays average force for each catheter, corrected for friction. Forces attributed to friction as measured with no aspiration for the $R^{4} Q$ and ACE 68 were 19.9 and 17.4 gram force respectively. The $R^{4} Q$ forces were more variable between trials but had a significantly higher average compared with the ACE 68 (Student T-Test, $\mathrm{P}<0.0001$ ).

\section{Impact of retraction on flow rate}

The $R^{4} Q$ system benefits from its dynamic length. The $R^{4} Q$ exhibits significantly greater suction force at the tip than the other devices tested despite a similar distal ID and surface area. Furthermore, once the $\mathrm{R}^{4} \mathrm{Q}$ is retracted completely into the guide catheter, the cross-sectional area presented to the clot is significantly increased, leading to even greater suction. When the $\mathrm{R}^{4} \mathrm{Q} 6 \mathrm{~F}$ is extended $25 \mathrm{~cm}$ out of the guide catheter, it exhibited a 39\% increase in flow rate over the standard catheter (figure 4). At full retraction, the flow rate of the $R^{4} Q 6 \mathrm{~F}$ was $117.2 \%$ greater. Since the length of a standard catheter remains constant during aspiration use, the flow rate does not change.
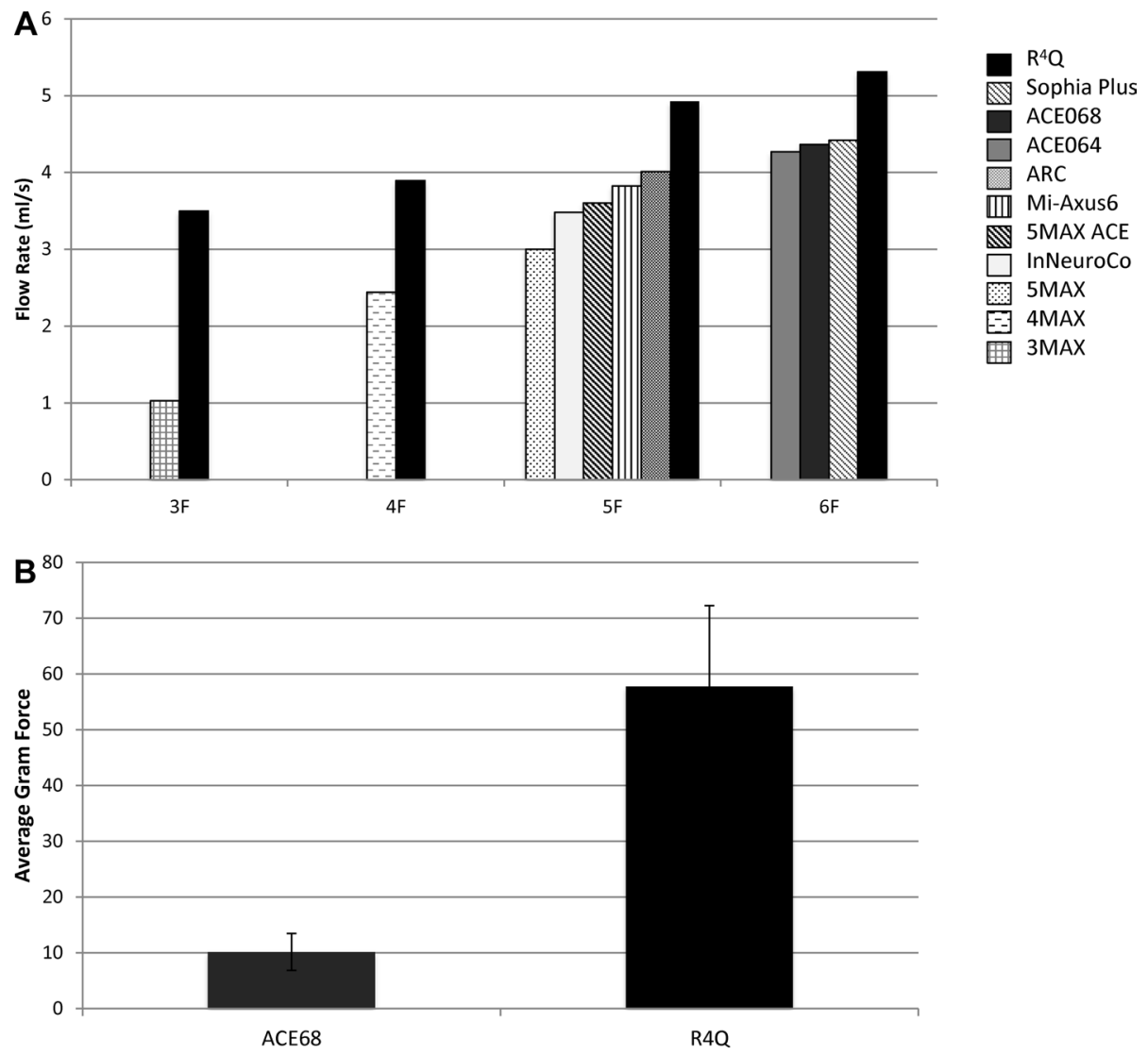

Figure 3 (A) Catheter flow rates by outer diameter size. (B) Average gram force measured for the ACE 68 and the $R^{4} Q$. 


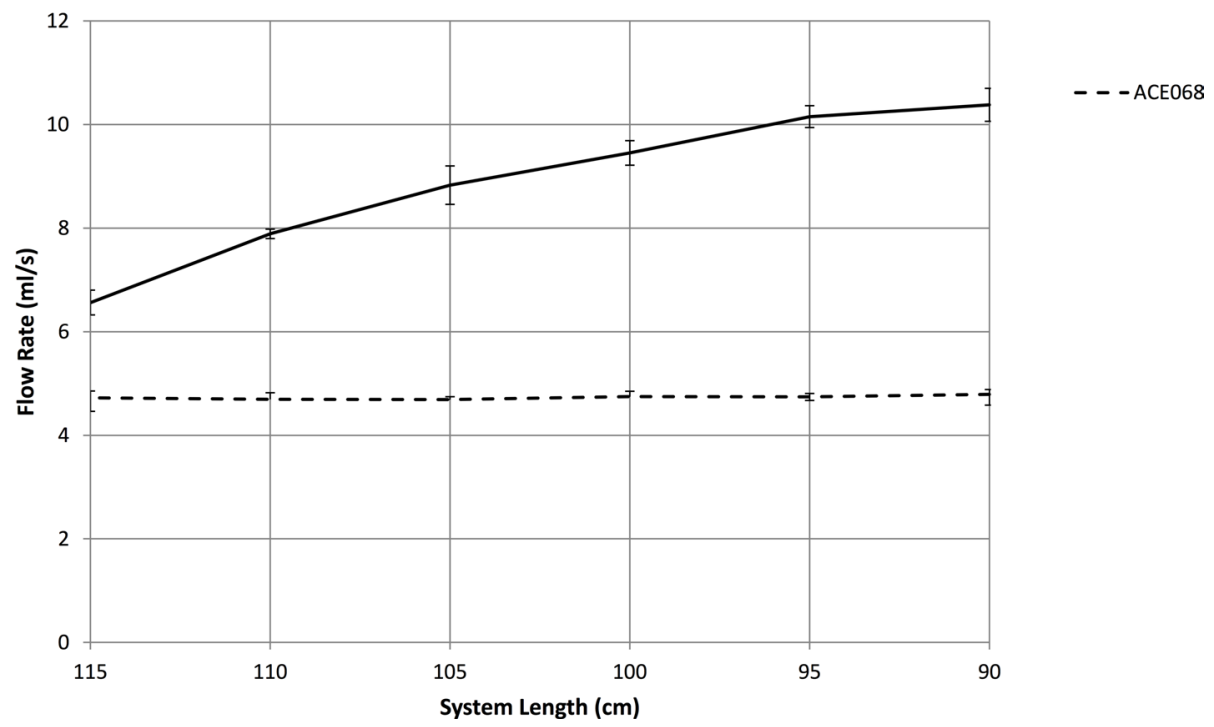

Figure $4 \quad R^{4} \mathrm{Q} 6 \mathrm{~F}$ flow rate (solid line) at multiple positions inside an $8 \mathrm{~F}$ guide catheter compared with the constant flow rate of a similarly sized uniform catheter (dashed line).

\section{Data reproducibility}

An additional sequence of 10 flow tests per catheter was completed to confirm the validity of the results. This replication portrays the precision of the entire experimental design. A two-sample T-test conducted with JMP Pro 13 software presented a significant difference between the flow rates of the $\mathrm{R}^{4} \mathrm{Q} 6 \mathrm{~F}$ and a uniformly sized catheter, the ACE $68(\mathrm{n}=10$ for each device, $\mathrm{P}<0.0001$ ). The $\mathrm{SD}$ for the $\mathrm{R}^{4} \mathrm{Q} 6 \mathrm{~F}$ and the ACE 68 were $0.0544 \mathrm{~mL} / \mathrm{s}$ and $0.0751 \mathrm{~mL} / \mathrm{s}$ respectively, accounting for $0.98 \%$ and $1.59 \%$ of the average flow rate values.

\section{DISCUSSION}

In the current study we demonstrated profound increases in flow rate and tip force in the $\mathrm{R}^{4} \mathrm{Q}$ catheter compared with standard suction catheters. These increases were correlated with the effective diameter of the $\mathrm{R}^{4} \mathrm{Q}$, which harnesses the large ID of the guide catheter to improve suction. In effect, the $R^{4} Q$ achieves markedly improved performance without the need for larger ID catheters. Notably, percent increases in flow rate were greatest in the smallest diameter system comparisons, offering the promise of improved suction embolectomy in narrow, distal branches. Finally, we demonstrated that suction forces increase when the tip of the $\mathrm{R}^{4} \mathrm{Q}$ is retracted through the guide, which will likely diminish the risk of distal emboli migration caused by lack of adherence to the catheter tip. Taken together, these findings illuminate the differences between the $\mathrm{R}^{4} \mathrm{Q}$ 's alternative design and classic suction catheters. Unlike standard catheters, the $R^{4} Q$ system optimizes the guide catheter ID at the proximal end of the system. In addition, the ability of the $\mathrm{R}^{4} \mathrm{Q}$ system to shorten during use further improves aspiration rate and force. These properties have the potential to translate into clinical advances in aspiration thrombectomy.

Prior in vitro studies of aspiration catheter flow have shown that larger ID catheters exhibit higher flow rates and tip forces due to greater surface area at the tip ${ }^{26-28}$ and catheter diameter has a correlation with thrombectomy success in coronary aspiration thrombectomy to treat acute myocardial infarction. ${ }^{29}$ Catheters providing high flow rates to dynamically pull the clot into the catheter tip and greater tip force to keep the clot suctioned to the tip may be more successful clinically. ${ }^{81130}$ These studies have focused on tip characteristics while we have emphasized the importance of the overall system dimensions. Significant increases in aspiration force observed in the $R^{4} \mathrm{Q}$ present minimal additional procedural risk in preclinical observations. Furthermore, aspiration thrombectomy in general results in less damage to vessel vasculature than stent retriever thrombectomy. ${ }^{31}$

This study is limited by the mathematical assumptions of the HPL, namely that flow of Newtonian fluid is laminar and nonaccelerating through a circular tube significantly longer than its diameter. It is important to note that the HPL is ideal for a tube of constant circular cross-section. Although some of the catheters in this study do not have constant IDs, the HPL is used as an approximation for the physical relationships observed. The highly tortuous nature of neurovascular anatomy undoubtedly affects fluid flow dynamics and should be investigated further. It is also important to note that fluidic properties of water are similar but not identical to human blood. Blood is more viscous than water and is classified as a non-Newtonian fluid. However, we found that while flow results for one catheter differ between water and glycerol, the comparative relationship across catheters does not vary significantly. Nonetheless, these in vitro results are approximations and should be supplemented with clinical assessment.

In addition, the tip force measured here does not represent a fully sealed catheter tip but rather it mimics a more realistic corking scenario in which the clot does not completely seal the tip interface. Previous work has revealed that catheters of varying diameters relay similar vacuum pressures but the theoretical amount of suction force relies on the area via $\mathrm{F}=\mathrm{P} * \mathrm{~A}$ where $\mathrm{P}$ is vacuum pressure and $\mathrm{A}$ is catheter area. ${ }^{27}$ While this relationship applies to closed, static catheter systems, if there is any fluid or air moving through the system, more complicated physics apply. If the clot does fully obstruct the catheter tip from fluid and air, the clot itself shares properties of a highly viscous liquid and obeys dynamic fluid laws. Additionally, the measured flow rate increases as the system length decreased by retracting the $\mathrm{R}^{4} \mathrm{Q}$ into the guide catheter. This cannot be explained by the pressure-derived force since the area remains constant as the $\mathrm{R}^{4} \mathrm{Q}$ is retracted. Therefore, we hypothesize that the force at the tip is also dictated by the HPL. 
By leveraging established theory in fluid mechanics, the $\mathrm{R}^{4} \mathrm{Q}$ aspiration can deliver superior suction to many areas of the neurovasculature, even distal regions of the MCA. With this device, the complexity and time required for a successful mechanical thrombectomy are expected to decrease significantly, resulting in more effective procedures and improved patient outcome. Future work will assess the performance of the catheter in a clinical study.

Contributors TDL, TS, AB, AMH, and DFK conceived of the presented idea and study design. AMH and JW collected and analyzed the data and drafted the manuscript. All authors reviewed the manuscript and delivered substantial feedback. Throughout the entire process, all authors provided critical input for planning, implementing, and presenting the study.

Funding The authors have not declared a specific grant for this research from any funding agency in the public, commercial, or not-for-profit sectors.

Competing interests DFK reports other from Marblehead Medical, grants from CURAM, outside the submitted work; In addition, DFK has a patent Balloon Guiding System pending. RH reports personal fees from MIVI Neuroscience, Inc., outside the submitted work. AMH reports grants from MIVI Neuroscience Inc., during the conduct of the study; In addition, AMH has a patent 14/949,574 pending to Mivi Neuroscience Inc. JW reports personal fees from MIVI Neuroscience, Inc., outside the submitted work. AB reports grants and personal fees from MICROVENTION, personal fees from MIVI NEUROSCIENCE, personal fees from SCIENTIA VASCULAR, personal fees from ENDOSTREAM MEDICAL, personal fees from BENDIT TECHNOLOGIES, personal fees from MAGNETO THROMBECTOMY SOLUTIONS, and personal fees from ANGIODYNAMICS, outside the submitted work.

Patient consent Not required.

Provenance and peer review Not commissioned; externally peer reviewed.

Open access This is an open access article distributed in accordance with the Creative Commons Attribution Non Commercial (CC BY-NC 4.0) license, which permits others to distribute, remix, adapt, build upon this work non-commercially, and license their derivative works on different terms, provided the original work is properly cited, appropriate credit is given, any changes made indicated, and the use is non-commercial. See: http://creativecommons.org/licenses/by-nc/4.0/.

\section{REFERENCES}

1 Goyal M, Demchuk AM, Menon BK, et al. Randomized assessment of rapid endovascular treatment of ischemic stroke. N Engl J Med 2015;372:1019-30.

2 Jovin TG, Chamorro A, Cobo E, et al. Thrombectomy within 8 hours after symptom onset in ischemic stroke. N Engl J Med 2015;372:2296-306.

3 Saver IL, Goyal M, Bonafe A, et al. Stent-retriever thrombectomy after intravenous t-PA vs. t-PA alone in stroke. N Engl J Med 2015;372:2285-95.

4 Campbell BC, Mitchell PJ, Kleinig TJ, et al. Endovascular therapy for ischemic stroke with perfusion-imaging selection. N Eng/ J Med 2015;372:1009-18.

5 Berkhemer OA, Fransen PS, Beumer D, et al. A randomized trial of intraarterial treatment for acute ischemic stroke. N Engl I Med 2015;372:11-20.

6 Fargen KM, Fiorella DJ, Mocco J. Practice makes perfect: establishing reasonable minimum thrombectomy volume requirements for stroke centers. I Neurointerv Surg 2017:9:717-9.

7 Kim SK, Yoon W, Moon SM, et al. Outcomes of manual aspiration thrombectomy for acute ischemic stroke refractory to stent-based thrombectomy. J Neurointerv Surg 2015;7:473-7.
8 Turk AS, Spiotta A, Frei D, et al. Initial clinical experience with the ADAPT technique: a direct aspiration first pass technique for stroke thrombectomy. J Neurointerv Surg 2014;6:231-7.

9 Turk AS, Turner R, Spiotta A, et al. Comparison of endovascular treatment approaches for acute ischemic stroke: cost effectiveness, technical success, and clinical outcomes. J Neurointerv Surg 2015;7:666-70.

10 Frei D, Gerber J, Turk A, et al. The SPEED study: initial clinical evaluation of the Penumbra novel 054 reperfusion catheter. J Neurointerv Surg 2013;5(Suppl 1):i74-6.

11 John S, Hussain MS, Toth G, et al. Initial experience using the 5MAXACE reperfusion catheter in intra-arterial therapy for acute ischemic stroke. I Cerebrovasc Endovasc Neurosurg 2014;16:350-7.

12 Meyne JK, Zimmermann PR, Rohr A, et al. Thrombectomy vs. systemic thrombolysis in acute embolic stroke with high clot burden: a retrospective analysis. Rofo 2015:187:555-60.

13 Turk AS, Frei D, Fiorella D, et al. ADAPT FAST study: a direct aspiration first pass technique for acute stroke thrombectomy. J Neurointerv Surg 2014;6:260-4.

14 Jankowitz B, Aghaebrahim A, Zirra A, et al. Manual aspiration thrombectomy. Stroke 2012;43:1408-11.

15. Premat $K$, Bartolini B, Baronnet-Chauvet $F$, et al. Single-center experience using the 3 max reperfusion catheter for the treatment of acute ischemic stroke with distal arterial occlusions. Clin Neuroradiol 2017:1-10.

16. Lapergue B, Blanc R, Gory B, et al. Effect of endovascular contact aspiration vs stent retriever on revascularization in patients with acute ischemic stroke and large vessel occlusion: the aster randomized clinical trial. JAMA 2017;318:443-52.

17 Vargas J, Spiotta AM, Fargen K, et al. Experience with A Direct Aspiration First Pass Technique (ADAPT) for thrombectomy in distal cerebral artery occlusions causing acute ischemic stroke. World Neurosurg 2017;99:31-6.

18 Millikan JS, Cain TL, Hansbrough J. Rapid volume replacement for hypovolemic shock: a comparison of techniques and equipment. J Trauma 1984:24:428-31.

19 Jain KK. Some observations on the anatomy of the middle cerebral artery. Can J Surg 1964;7:134-9.

20 Akers A, Gassman M, Smith R, et al. Flow Division. Hydraulic power system analysis. New York: CRC Press, 2006:299-333.

21 Iserson KV, Reeter AK, Criss E, et al. Comparison of flow rates for standard and largebore blood tubing. West J Med 1985;143:183-5.

22 Esposito A, Thrower JR. A Simplified Method for Analyzing Circuits by Analogy. Machine design: Delmar Publishers, 1969:173-7.

23. Kirby BJ. Micro-and nanoscale fluid mechanics: transport in microfluidic devices: Cambridge University Press, 2010. https://books.google.com/books?id= y7PB9f5zmU4C

24 Hodge D, Fleisher G. Pediatric catheter flow rates. Am J Emerg Med 1985;3:403-7.

25 Graber D, Dailey RH. Catheter flow rates updated. J Am Coll Emerg Phys 1977;6:518.

26 Hu YC, Stiefel MF. Force and aspiration analysis of the ADAPT technique in acute ischemic stroke treatment. J Neurointerv Surg 2016;8:244-6.

27 Froehler MT. Comparison of vacuum pressures and forces generated by different catheters and pumps for aspiration thrombectomy in acute ischemic stroke. Interv Neurol 2017;6:199-206.

28 Nikoubashman 0, Nikoubashman A, Büsen M, et al. Necessary catheter diameters for mechanical thrombectomy with ADAPT. AJNR Am J Neuroradiol 2017:38:2277-81.

29 Ahmed SM, Latib A. A review of thrombectomy devices. Expert Rev Med Devices 2012;9:513-20.

30 Shi Y, Cheshire D, Lally F, et al. Suction force-suction distance relation during aspiration thrombectomy for ischemic stroke: a computational fluid dynamics study. Phys Med 2017;3:1-8.

31 Pearce G, Perkinson ND, Wong J, et al. In vitro testing of a new aspiration thrombus device. J Stroke Cerebrovasc Dis 2010;19:121-9. 